\title{
Correlates of depressive symptoms among Latino and Non-Latino White adolescents: Findings from the 2003 California Health Interview Survey
}

\author{
Rafael T Mikolajczyk ${ }^{1}$, Maren Bredehorst ${ }^{1}$, Nadia Khelaifat ${ }^{1}$, Claudia Maier ${ }^{1}$ \\ and Annette E Maxwell*1,2
}

\begin{abstract}
Address: ${ }^{1}$ School of Public Health, Department of Public Health Medicine, University of Bielefeld, Bielefeld, Germany and ${ }^{2}$ School of Public Health and Jonsson Comprehensive Cancer Center, Division of Cancer Prevention \& Control Research, University of California, Los Angeles, 650 Charles Young Dr. South, Room A2-125, CHS, Los Angeles, CA 90095-6900. USA

Email: Rafael T Mikolajczyk - rmikolajczyk@uni-bielefeld.de; Maren Bredehorst - maren.bredehorst@uni-bielefeld.de; Nadia Khelaifat - nadia.khelaifat1@uni-bielefeld.de; Claudia Maier - clamaier@gmx.de; Annette E Maxwell* - amaxwell@ucla.edu

* Corresponding author
\end{abstract}

Published: 2I February 2007

BMC Public Health 2007, 7:21 doi:|0.1 |86/147|-2458-7-21
Received: 3 July 2006

Accepted: 21 February 2007

This article is available from: http://www.biomedcentral.com/I47I-2458/7/2I

(C) 2007 Mikolajczyk et al; licensee BioMed Central Ltd.

This is an Open Access article distributed under the terms of the Creative Commons Attribution License (http://creativecommons.org/licenses/by/2.0), which permits unrestricted use, distribution, and reproduction in any medium, provided the original work is properly cited.

\begin{abstract}
Background: The prevalence of depression is increasing not only among adults, but also among adolescents. Several risk factors for depression in youth have been identified, including female gender, increasing age, lower socio-economic status, and Latino ethnic background. The literature is divided regarding the role of acculturation as risk factor among Latino youth. We analyzed the correlates of depressive symptoms among Latino and NonLatino White adolescents residing in California with a special focus on acculturation.

Methods: We performed an analysis of the adolescent sample of the 2003 California Health Interview Survey, which included 3,196 telephone-interviews with Latino and Non-Latino White adolescents between the ages of 12 and 17. Depressive symptomatology was measured with a reduced version of the Center for Epidemiologic Studies Depression Scale. Acculturation was measured by a score based on language in which the interview was conducted, language(s) spoken at home, place of birth, number of years lived in the United States, and citizenship status of the adolescent and both of his/her parents, using canonical principal component analysis. Other variables used in the analysis were: support provided by adults at school and at home, age of the adolescent, gender, socioeconomic status, and household type (two parent or one parent household).

Results: Unadjusted analysis suggested that the risk of depressive symptoms was twice as high among Latinos as compared to Non-Latino Whites $(10.5 \%$ versus $5.5 \%, p<0.00 \mathrm{I})$. The risk was slightly higher in the low acculturation group than in the high acculturation group $(13.1 \%$ versus $9.7 \%, p=0.12)$. Similarly, low acculturation was associated with an increased risk of depressive symptoms in multivariate analysis within the Latino subsample (OR I.54, Cl 0.97-2.44, $\mathrm{p}=0.07$ ). Latino ethnicity emerged as risk factor for depressive symptoms among the strata with higher income and high support at home and at school. In the disadvantaged subgroups (higher poverty, low support at home and at school) Non-Latino Whites and Latinos had a similar risk of depressive symptoms.
\end{abstract}

Conclusion: Our findings suggest that the differences in depressive symptoms between Non-Latino Whites and Latino adolescents disappear at least in some strata after adjusting for socio-demographic and social support variables. 


\section{Background}

Depression is a very frequent health problem which is growing at an alarming rate. It has been suggested that if the trend persists, by 2020, depression will be the second biggest health care problem after heart disease worldwide [1]. The prevalence of depression is increasing not only among adults, but also among adolescents [2]. This increase is mostly related to the moderate forms of depressions without psychomotoric and physical symptoms [3]. Nevertheless, this form of depression is still strongly affecting health and quality of life of the patients. Population based studies show that at any one time between 10 and $15 \%$ of the child and adolescent population has some symptoms of depression [4]. Our paper focuses on symptoms of depression based on self-report.

Several risk factors for depression among adolescents have been identified, including female gender, increasing age, lower socio-economic status, and Latino ethnic background $[5,6]$. The effect of acculturation on depression has also been investigated. The term acculturation generally refers to the process whereby the attitudes and/or behaviors of persons from one culture are modified as a result of contact with a different culture. A recent literature review examined the association between acculturation and depression among Latinos. High acculturation was associated with a worse outcome in two studies, with a positive effect in one study, and had mixed or no effect on depression in three studies [7]. The author argues that past research was inconsistent in the measurement of acculturation or in the adjustment for possible confounding factors. In some cases, when studies have controlled for factors such as age, education or other factors, the effects of acculturation diminish or disappear [7]. In addition to demographic characteristics it has been suggested that social support and supervised care after school may be protective factors $[8,9]$.

The aim of our study is to investigate the association between demographic factors (age, gender, ethnic background, socio-economic status), acculturation, social support and depressive symptoms in a large populationbased sample of Latino and Non-Latino White adolescents residing in California.

\section{Methods}

\section{Sample and variables}

A secondary analysis was conducted using data from the adolescent sample of the 2003 California Health Interview Survey (CHIS) [10]. CHIS is a population-based, random-digit dial telephone survey which is representative for California's households in 2003. The analysis was based on 3,196 telephone-interviews with Latino and Non-Latino White adolescents between the ages of 12 and 17.

\section{Measure of depressive symptoms}

Depressive symptoms were measured according to a reduced version of the Center for Epidemiologic Studies Depression Scale (CES-D) following Radloff [11], who first adopted the CES-D Scale to children and adolescents. There were eight items in total, covering depressed affect (felt depressed, lonely, sad, could not shake off feeling sad and unhappy, felt life was a failure), happiness (were happy, enjoyed life), and retarded activity (did not want to do the things you usually do) during the past 7 days. Similarly to Radloff, the CHIS questionnaire did not ask for interpersonal aspects, because problematic peer relationships might be the norm for adolescents. There was a four point answer scale for the eight items (never, sometimes, a lot of the time, most of the time); for two of the items the scores were reversed, then the sum of the scores $(0,1,2,3)$ was calculated with higher scores indicating more symptoms.

Although the CES-D has been used as a screening instrument for depressive symptoms among adolescents, there are no established cutoff scores of the 8-item version of the CES-D Scale that was used in the CHIS. Cutoff scores of $\geq 8$ and $\geq 10$ have been used on the 10 item CES-D Scale in adult samples (e.g., [12]). Cutoff of $\geq 16$ indicates depressive symptoms in the original 20 item CES-D (maximum score $=60$ points), which was validated using DSM_III criteria. We set a cutoff score of $>10$ as an indictor for depressive symptoms for the 8 item CES-D (maximum score $=24$ ) in the CHIS sample, which corresponds to a cutoff score of $>25$ on the 20 item scale. Based on analyses by Roberts et al., [13] 25 is the midpoint in the "moderately depressed" category in a student sample that completed the 20-item CES-D.

Few studies have assessed psychometric properties of the CES-D Scale among adolescents from diverse ethnocultural groups [14-16]. These studies suggest that it is appropriate to use the CES-D among Mexican-American adolescents, since their depression symptomatology is very similar to that of their Anglo-American peers. In our sample, factor analysis yielded identical factor structure and similar factor loadings in all three groups. High internal reliability indicated high homogeneity of the scale: Cronbach's alpha of the 8-item CES-D scale ranged from .73 in the low acculturation Latino subgroup to .79 among Non-Latino Whites.

\section{Ethnic background and acculturation index}

Our analysis was based on data from Latino and Non-Latino White respondents. Within the Latino subgroup we computed an acculturation index based on the following variables: language in which the interview was conducted, language(s) spoken at home, place of birth, and number of years lived in the United States, citizenship status of the 
adolescent and both of his/her parents. The index was created using canonical principal component analysis (CAPCTA) [17], the nonparametric version of the principal component analysis, which has to be used when variables are either multinomial or ordinal. In a density plot the distribution of the acculturation index showed two clearly separated groups (see Figure 1.). Based on visual inspection, the index was dichotomized at 0.6 into high and low acculturation. The components of the acculturation index together with the categories of the acculturation index are presented in Table 1. The high acculturation Latino group was US born, bi-lingual and most of the interviews were conducted in English. The low acculturation Latino group was characterized by youth being foreign born and more frequent use of Spanish only.

Other variables used in the analysis

Support provided by adults at school and at home was each measured with 8 items assessing the presence of adults who cared about, listened to and encouraged the adolescent respondent. Using CAPCTA, these variables were combined into two separates scores which were dichotomized at the median into low and high categories. The correlation between the support variables was below 0.4 . Additionally we included in the analysis: age of the adolescent (in three groups 12-13,14-15, 16-17), gender, socio-economic status $(<200 \%$ poverty level and $\geq$ $200 \%$ poverty level), and household type (two parent or one parent household).

\section{Statistical analysis}

Factor analysis was conducted to confirm identical factor structure of the CES-D scale for all subgroups. Internal reliability of the scale was tested by Cronbach's alpha. Univariate analysis was performed by tabulation and chisquare tests between Non-Latino White and Latino adolescents with high or low level of acculturation. We used the conventional significance level $(\mathrm{p}<0.05)$. Univariate und multivariate logistic regression was used for the analysis of association between the risk of depressive symptoms and other variables. Multicollinearity test was performed based on the tolerance coefficient - no colline-

Table I: Ethnic, language and immigration characteristics by acculturation index

\begin{tabular}{|c|c|c|c|}
\hline & Non-Hispanic White & Latino (high acculturation) & Latino (low acculturation) \\
\hline Characteristics & $\begin{array}{c}N=\underset{\%}{2,071} \\
\end{array}$ & $\begin{array}{c}N=865 \\
\%\end{array}$ & $\begin{array}{c}N=260 \\
\%\end{array}$ \\
\hline \multicolumn{4}{|l|}{ Country of birth } \\
\hline US & 96.9 & 99.5 & \\
\hline Other & 3.1 & 0.5 & 100 \\
\hline \multicolumn{4}{|l|}{ Citizenship } \\
\hline Native & 96.9 & 99.5 & \\
\hline Naturalized & 1.8 & 0.5 & 20.8 \\
\hline Other & 1.3 & & 79.2 \\
\hline \multicolumn{4}{|l|}{ Living in the US } \\
\hline Born in the US & 96.9 & 99.5 & \\
\hline 10 or more years & 1.4 & 0.5 & 43.5 \\
\hline $5-9$ years & 0.9 & & 25.0 \\
\hline $2-4$ years & 0.5 & & 22.7 \\
\hline I or less years & 0.3 & & 8.8 \\
\hline \multicolumn{4}{|l|}{ Language at home } \\
\hline English & 85.6 & 24.3 & 1.5 \\
\hline English + other language & 13.2 & 67.2 & 69.6 \\
\hline Spanish & 1.2 & 8.6 & 28.8 \\
\hline \multicolumn{4}{|l|}{ Interview language } \\
\hline English & 99.7 & 87.4 & 47.3 \\
\hline Spanish & 0.3 & 12.6 & 52.7 \\
\hline \multicolumn{4}{|c|}{$\begin{array}{l}\text { Citizenship and immigration status } \\
\text { of mother }\end{array}$} \\
\hline Native & 88.6 & 39.3 & 1.9 \\
\hline Naturalized & 7.3 & 23.4 & 5.8 \\
\hline Other & 4.2 & 37.3 & 92.3 \\
\hline \multicolumn{4}{|c|}{$\begin{array}{l}\text { Citizenship and immigration status } \\
\text { of Father }\end{array}$} \\
\hline Native & 89.3 & 34.5 & 3.8 \\
\hline Naturalized & 6.7 & 26.9 & 14.6 \\
\hline Other & 4.0 & 38.6 & 81.5 \\
\hline
\end{tabular}




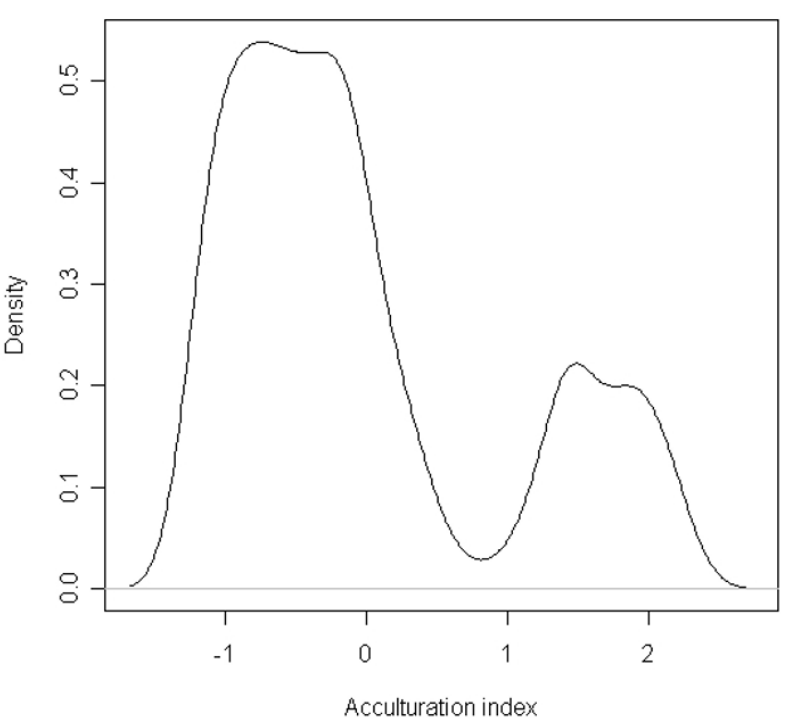

Figure I

Distribution of the acculturation index (Kernel density plot).

arity problems were detected for the analyzed variables. We also examined the effect of acculturation in the Latino subsample, using a continuous acculturation score (data not shown) and in a second step as a dichotomous variable. Finally, the possibility of effect modification between ethnic background and other variables was investigated. The modeling strategy followed Hosmer and Lemeshow [18]. All variables were included in a multiple logistic regression model. All two-ways interactions were investigated in separate steps with the main effects model. Interactions significant at the 0.05 level (based on Wald-test) were included jointly in the preliminary final model. The final model was obtained by removing effects which were not significant at the 0.05 level. For variables with effect modification the effect of ethnic background was calculated for different strata. All analyses were performed using SPSS 12.0.

\section{Results}

\section{Description of the sample}

The total sample consisted of 3196 adolescents: 2071 Non-Latino White youth, 865 Latino youth in the high acculturation category and 260 in the low acculturation category. The three groups were significantly different with respect to most socio-demographic characteristics (see Table 2). Latino youth came more frequently from lower income households, and reported lower support at home or at school. The low acculturation Latino group was the most disadvantaged in terms of social support and income. However, more Latino youth in the low acculturation group came from two parent households as compared to high acculturation Latinos and Non-Latino Whites.

\section{Characteristics associated with depressive symptoms}

Scores on the 8-item CES-D Scale ranged from 0-24, with a mean score of 4.4 and standard deviation of 3.7. A total of 232 adolescents (7.3\% of the sample) had scores $>10$ and were classified as having symptoms of depression (see Table 3). Based on univariate analysis, a significantly larger proportion of Latino youth had depressive symptoms as compared to Non-Latino Whites $(10.5 \%$ versus $5.5 \%, \mathrm{p}<0.001)$. Although more low acculturation Latinos had symptoms of depression than high acculturation Latinos (13.1\% versus 9.7\%), this difference was not statistically significant (chi-square, $\mathrm{p}=0.12$ ). Females, youth living in households below $200 \%$ poverty level, those living in a one parent household and those who received low support at home and at school were significantly more likely to have symptoms of depression. Age was not associated with symptoms of depression in this sample.

In multivariate analysis, not accounting for effect modification, the impact of ethnic background and acculturation decreased as compared to univariate analysis (Table 3, columns 4 and 5). In this analysis, the odds of depressive symptoms were only increased among low acculturation Latinos as compared to Non-Latino Whites. Poverty level and low level of support at home no longer emerged as independent predictors of depressive symptoms. In this analysis, the most important predictors of depressive symptoms were low support at school, female gender, being classified as low acculturation Latino and coming from a one parent household.

\section{Characteristics associated with depressive symptoms in the Latino subsample}

We examined independent predictors of depressive symptoms among Latinos by limiting the analysis to the Latino subsample. Similar to the multivariate analysis in the whole sample shown in Table 3, female gender and low support at school emerged as risk factors in the Latino subsample (Table 4). In the low acculturation group the odds of depressive symptoms were $50 \%$ higher than in the high acculturation group, but the effect did not reach statistical significance. There was no substantial change in effects of other variables after the inclusion of the acculturation variable in the joint model, only the impact of poverty level slightly decreased. There was also no evidence of effect modification in the Latino subsample which was assessed by significance of interaction terms (data not shown). 
Table 2: Socio-demographic characteristics by ethnicity and acculturation

\begin{tabular}{|c|c|c|c|}
\hline & Non-Latino White & Latino (high acculturation) & Latino (low acculturation) \\
\hline Characteristics & $\begin{array}{c}N=\underset{\%}{207 I} \\
\end{array}$ & $\begin{array}{c}N=865 \\
\%\end{array}$ & $\begin{array}{c}N=260 \\
\%\end{array}$ \\
\hline \multicolumn{4}{|l|}{ Age* } \\
\hline $12-13$ years & 32.7 & 40.5 & 31.5 \\
\hline $14-15$ years & 33.9 & 33.6 & 31.5 \\
\hline $16-17$ years & 33.3 & 25.9 & 36.9 \\
\hline \multicolumn{4}{|l|}{ Gender } \\
\hline Male & 50.4 & 51.1 & 54.2 \\
\hline Female & 49.6 & 48.9 & 45.8 \\
\hline \multicolumn{4}{|l|}{ Poverty level* } \\
\hline$<200 \%$ & 16.7 & 60.8 & 88.1 \\
\hline $200 \%$ or more & 83.3 & 39.2 & 11.9 \\
\hline \multicolumn{4}{|l|}{ Household Type* } \\
\hline Both parents & 75.0 & 72.6 & 83.8 \\
\hline One parent & 25.0 & 27.4 & 16.2 \\
\hline \multicolumn{4}{|l|}{ Support at home* } \\
\hline Low & 44.5 & 57.8 & 63.8 \\
\hline High & 55.5 & 42.2 & 36.2 \\
\hline \multicolumn{4}{|l|}{ Support at school* } \\
\hline Low & 42.1 & 56.2 & 65.4 \\
\hline High & 57.9 & 43.8 & 34.6 \\
\hline
\end{tabular}

*significant differences between the three subgroups, $p<.001$, chi-square test

Table 3: Characteristics associated with depressive symptoms in univariate and multivariate analysis (main effects only, $\mathrm{N}=3,196)$

\begin{tabular}{|c|c|c|c|c|}
\hline Characteristics & $\begin{array}{c}\text { Depressive Symptoms N } \\
\text { (\%) }\end{array}$ & chi-square $p$-value & Univariate OR $(95 \% \mathrm{Cl})$ & Multivariate* OR $(95 \% \mathrm{Cl})$ \\
\hline Total sample & $232(7.3)$ & & - & - \\
\hline Ethnic background & & $<0.001$ & & \\
\hline Non-Latino White & $114(5.5)$ & & 1 & 1 \\
\hline $\begin{array}{l}\text { Latino (high } \\
\text { acculturation) }\end{array}$ & $84(9.7)$ & & $1.85(1.38-2.48)$ & $1.39(1.00-1.95)$ \\
\hline $\begin{array}{l}\text { Latino (low } \\
\text { acculturation) }\end{array}$ & $34(13.1)$ & & $2.58(1.72-3.88)$ & $1.81(1.12-2.93)$ \\
\hline Age & & 0.7 & & \\
\hline $12-13$ & $75(6.8)$ & & $0.92(0.66-1.23)$ & $0.96(0.68-1.35)$ \\
\hline $14-15$ & $83(7.7)$ & & $1.06(0.76-1.46)$ & $1.10(0.78-1.54)$ \\
\hline $16-17$ & $74(7.3)$ & & 1 & 1 \\
\hline Gender & & $<0.001$ & & \\
\hline Male & $78(4.8)$ & & 1 & 1 \\
\hline Female & $154(9.8)$ & & $2.16(1.63-2.86)$ & 2.30 (1.72-3.07) \\
\hline Poverty Level & & $<0.001$ & & \\
\hline$\geq 200 \%$ & $116(5.5)$ & & I & I \\
\hline$<200 \%$ & $116(10.5)$ & & $2.01(1.54-2.63)$ & $1.34(0.96-1.87)$ \\
\hline Household Type & & $<0.001$ & & \\
\hline Both parents & $150(6.3)$ & & 1 & I \\
\hline One parent & $82(10.3)$ & & $1.72(1.30-2.28)$ & $1.55(1.15-2.09)$ \\
\hline Support at home & & $<0.001$ & & \\
\hline High & $88(5.5)$ & & 1 & I \\
\hline Low & $144(9.1)$ & & $1.72(1.31-2.27)$ & $1.16(0.87-1.57)$ \\
\hline Support at school & & $<0.001$ & & \\
\hline High & $52(3.1)$ & & 1 & I \\
\hline Low & $180(11.8)$ & & 4.16 (3.03-5.7I) & $3.52(2.52-4.92)$ \\
\hline
\end{tabular}

*adjusted for all other variables in the table 
Table 4: Characteristics associated with depressive symptoms in the Latino subsample $(\mathbf{N}=I, I 25)$

\begin{tabular}{|c|c|c|c|c|}
\hline \multirow[b]{2}{*}{ Characteristics } & \multicolumn{2}{|c|}{ Model not including acculturation } & \multicolumn{2}{|c|}{ Model including acculturation } \\
\hline & OR $(95 \% \mathrm{Cl})^{*}$ & $\mathrm{P}$-value & OR $(95 \% \mathrm{Cl})^{*}$ & $\mathrm{P}$-value \\
\hline Acculturation low vs. high & - & & $1.54(0.97-2.44)$ & 0.07 \\
\hline Age: $12-13$ vs. $16-17$ & $1.22(0.75-2.00)$ & 0.4 & $1.30(0.79-2.14)$ & 0.30 \\
\hline Age: $14-15$ vs. $16-17$ & $1.21(0.73-2.01)$ & 0.5 & $1.26(0.75-2.09)$ & 0.39 \\
\hline Gender: Female vs. male & $2.60(1.72-3.93)$ & $<0.001$ & 2.64 ( $1.74-3.99)$ & $<0.001$ \\
\hline$<200 \%$ poverty level vs. $>200 \%$ & $0.96(0.63-1.46)$ & 0.8 & $0.86(0.55-1.33)$ & 0.50 \\
\hline Household type: One parent vs. both & $1.29(0.84-1.99)$ & 0.2 & $1.37(0.88-2.13)$ & 0.16 \\
\hline Support at home: low vs. high & $0.85(0.57-1.29)$ & 0.5 & $0.84(0.55-1.27)$ & 0.40 \\
\hline Support at school: low vs. high & $2.53(1.60-4.00)$ & $<0.001$ & $2.50(1.58-3.97)$ & $<0.001$ \\
\hline
\end{tabular}

*adjusted for all other variables in the table

\section{Ethnic differences in depressive symptoms in different strata of covariates}

The comparison of the results in the Latino subsample (Table 4) and Latino and Non-Latino White combined sample (Table 3 ) revealed a strong effect modification. The poverty level, support at home and support at school had consistently a weaker association with depressive symptoms in the Latino sample than in the whole sample. This was confirmed in the formal analysis of interactions and the stratified results are presented in Table 5. The highest odds ratios were found in the more advantaged strata: the odds ratios for Latinos to have depressive symptoms as compared to Non-Latino Whites ranged from 2.1 in the strata with poverty level $\geq 200 \%$ to 3.29 in the strata with high support at school. The odds ratio of having depressive symptoms among Latinos as compared to Non-Latino Whites was 4.62 in the strata with high income and high support both at school and at home. The odds of having depressive symptoms were not different between Latinos and Non-Latino Whites in the strata that had lower levels of income and support at home. Predictors of depressive symptoms also varied somewhat in the male and female subsamples (Table 6). In both gender groups, low support at school remained the most important predictor of depressive symptoms. Among males, additional predictors were low support at home and coming from a one parent household which did not emerge as risk factors among females. Among females but not among males, low family income and being $14-15$ years old emerged as risk factors for depressive symptoms. Ethnicity emerged as risk factor for depressive symptoms only among females.

\section{Discussion}

We conducted extensive analyses in a population-based sample of Latino and Non-Latino White adolescents to examine associations between depressive symptoms and socio-demographic variables (age, gender, ethnicity, income, one parent versus two parent household type), acculturation, and social support at home and at school.
Crude analyses suggested that the risk of depressive symptoms was twice as high among Latinos as compared to Non-Latino Whites (10.5\% versus $5.5 \%$ ). Other risk factors included female gender, low household income, one parent household, and low support at home and at school. All of these factors have been reported as risk factors for depressive symptoms among Latinos and other ethnic groups $[6,8,9,19]$.

However, when all risk factors were considered simultaneously in a multivariate analysis, only four independent risk factors emerged: having low support at school, being female, being classified as low acculturation Latino and coming from a one parent household. In a stratified analysis, risk factors that were unique to males were low support at home and coming from a one parent household. Ethnicity was not a risk factor in this stratified analysis, suggesting that these risk factors are similar among both Non-Latino White and Latino male adolescents regardless of ethnic background. Almost one third of children less than 18 years of age in California (29\%) live in one parent households: $21 \%$ live in mother only households and $7 \%$ in father only households [20]. Thus, boys are more likely than girls to live in a one parent household with a parent of the opposite gender. It may be that males growing up without a father in the household are either experiencing something or lacking something, such as for example a male role model, that increases their risk of depressive symptoms. Patten and colleagues [8] analyzed data of a large sample of California adults and also found higher rates of depressive symptoms among adolescents living in one parent households than in those living in two parent households. Their study showed highest rates of depressive symptoms among girls living in father only households (25.1\% vs. 19.35 in mother only households), whereas the rates of depressive symptoms for boys were around $16 \%$ for both father or mother only households [8]. The relative effect of single parent household (which are predominantly single mother households) was stronger for boys than for girls in our analysis. Further 
Table 5: Ethnic differences in depressive symptoms in different strata of covariates

\begin{tabular}{|c|c|}
\hline Characteristics & OR $(95 \% \mathrm{Cl})^{*}$ \\
\hline \multicolumn{2}{|c|}{ Within poverty level $\geq 200$} \\
\hline Non-Latino White & I \\
\hline Latino & $2.10(1.38-3.19)$ \\
\hline \multicolumn{2}{|c|}{ Within poverty level $<200$} \\
\hline Non-Latino White & I \\
\hline Latino & $0.96(0.62-1.50)$ \\
\hline \multicolumn{2}{|c|}{ Within high support at home } \\
\hline Non-Latino White & I \\
\hline Latino & $2.75(1.75-4.32)$ \\
\hline \multicolumn{2}{|c|}{ Within low support at home } \\
\hline Non-Latino White & 1 \\
\hline Latino & $1.28(0.90-1.82)$ \\
\hline \multicolumn{2}{|c|}{ Within high support at school } \\
\hline Non-Latino White & 1 \\
\hline Latino & $3.29(1.86-5.82)$ \\
\hline \multicolumn{2}{|c|}{ Within low support at school } \\
\hline Non-Latino White & I \\
\hline Latino & $1.41(1.02-1.93)$ \\
\hline \multicolumn{2}{|c|}{ Within: poverty level $\geq 200$, high support at school and at home } \\
\hline Non-Latino White & I \\
\hline Latino & $4.62(1.63-13.10)$ \\
\hline
\end{tabular}

*all models include: age, gender, poverty level, ethnic background, support at home and support at school (where appropriate)

analyses by Patten and colleagues [8] revealed that household type has to be considered in conjunction with parental support, as even in a two parent household risk of depression was increased if the adolescents perceived that they were not able to talk to either parent about their problems. Clearly, the complex relationship between depression, household type and parental support and the mechanisms of how these variables may relate to depression need to be further studied.

Risk factors of depressive symptoms that were unique to females in our sample were Latino ethnicity, age 14-15 and low household income. Latino females emerged as risk group for depressive symptoms in both a gender stratified analysis and in an analysis limited to the Latino subsample. Interestingly, the age group 14-15 years had the highest risk of depressive symptoms among females, but the lowest risk for males. Thus, in the combined analysis, the risk estimates were averaged and age did not emerge as a risk factor for depressive symptoms. Our findings suggest that boys and girls show different profiles of correlates and probable risk factors for depressive symptoms. Others have suggested that risk factors for depression such as stress and social support may have a greater impact among girls than among boys [9]. Future studies need to further evaluate gender differences in rates and risk factors of depression as gender specific intervention programs may be needed.

In our sample, low support at school was the strongest risk factor for depressive symptoms for both males and females. This variable captured respondents' perceptions of the availability of a teacher or other adult at school who "noticed when they were not there, listened to them when

Table 6: Gender differences in predictors of depressive symptoms: Separate analysis for males and females

\begin{tabular}{|c|c|c|c|c|}
\hline & Male $(N=2048)$ & & Female $(N=1962)$ & \\
\hline Characteristics & OR $(95 \% \mathrm{Cl})^{*}$ & P-value & OR $(95 \% \mathrm{Cl})^{*}$ & P-value \\
\hline Latino versus Non-Latino White & $1.27(0.74-2.19)$ & 0.39 & $1.60(1.08-2.39)$ & 0.02 \\
\hline Age: $12-13$ vs. $16-17$ & $1.00(0.58-|.7|)$ & 0.99 & $0.92(0.59-1.44)$ & 0.71 \\
\hline Age: $14-15$ vs. $16-17$ & $0.56(0.31-1.02)$ & 0.06 & $1.51(0.99-2.29)$ & 0.06 \\
\hline$<200 \%$ poverty level vs. $>200 \%$ & $1.12(0.64-1.94)$ & 0.70 & $1.54(1.03-2.30)$ & 0.04 \\
\hline Household type: One parent vs. both & $2.36(1.46-3.8 I)$ & $<0.001$ & $1.16(0.79-1.70)$ & 0.45 \\
\hline Support at home: low vs. high & $1.73(1.01-2.98)$ & 0.05 & $0.97(0.68-1.39)$ & 0.86 \\
\hline Support at school: low vs. high & $3.21(1.80-5.72)$ & $<0.001$ & $3.78(2.5|-5.7|)$ & $<0.001$ \\
\hline
\end{tabular}

* adjusted for all other variables in the tables 
they had something to say, told them when they did a good job, always wanted them to do their best, and noticed when they were in a bad mood". Thus, teachers and school counselors are important sources of support, and need to be trained to recognize symptoms and risk factors of depression. They also need to be given the time to pay attention to individual students.

A multivariate analyses taking into account existing interactions between socio-economic status, perceived support and ethnicity provided a profile of depressive symptoms that was even more detailed. When we examined different strata of household income and support, either at home or at school, Latino ethnicity emerged as risk factor for depressive symptoms only among the strata with higher income and high support at home and at school. While this finding is counterintuitive at first, it suggests that high economic status and social support are protective factors only among Non-Latino Whites. We have not been able to find any literature that is investigating this hypothesis. An alternative interpretation relates to the association between depressive symptoms and perceived discrimination. Several studies suggest that higher income is associated with more perceived discrimination and that discrimination is a risk factor for depression [21,22]. Since CHIS does not assess perceived discrimination, we were not able to examine this relationship. We found no ethnic differences between Latino and Non-Latino Whites in the prevalence of depressive symptoms in the strata with low income or low social support at home

Although our data suggest several correlations between socio-demographic characteristics, social support and depressive symptoms, the causal nature of these relationships is ambiguous given the cross sectional study design. As pointed out by others [8], depressed adolescents may be less inclined to form supportive relationships with parents, teachers or peers, and less likely to perceive relationships as supportive, and to report supportive relationships. Another limitation of our data set is that several variables that have been shown to be risk factors for depression, such as stressful life events [9], perceived discrimination and low self esteem [21-23], being involved in bullying either as a perpetrator or as a victim [5], affiliation with high-versus low status peer crowd, negative or positive qualities of friendships, and presence or absence of romantic relationships [24] were not available. Finally, as in many other studies, our measure of acculturation may not have captured aspects of the acculturation process that are related to depression. Although we attempted to include all data related to the acculturation experience that were available in this data set in developing an acculturation scale, and although we used a method that has the advantage of not making inappropriate statistical assumptions, the dichotomized accultur- ation variable that we created was almost identical to a simple dichotomization based on country of birth (US versus other). Finally, our sample of low acculturation Latino respondents was relatively small and given that most Latinos living in California are from Mexico, findings may not be generalizable to those with different heritage. However, despite these limitations, our analysis adds some information to the sparse literature on depression among ethnically diverse adolescents.

\section{Conclusion}

Our findings suggest that differences in depressive symptoms between Non-Latino Whites and Latino adolescents disappear at least in some strata after adjusting for sociodemographic and social support variables and gave rise to some interesting hypotheses regarding modifiers of depression such as household income, social support and gender. These hypotheses should be further investigated in order to identify groups that are at high risk for depression and could benefit from interventions.

\section{Competing interests}

The authors declare that they have no competing interests.

\section{Authors' contributions}

RTM analyzed the data and participated in the interpretation of the results and the writing of the final version of the manuscript. $\mathrm{MB}, \mathrm{NK}, \mathrm{CM}$ developed the research question, performed preliminary analyses and wrote a few sections of the manuscript as part of a class assignment. AEM participated in the interpretation of the results and wrote large parts of the final version of the manuscript. All authors approved the final version of the manuscript.

\section{Acknowledgements}

$\mathrm{MB}, \mathrm{NK}$ and $\mathrm{CM}$ were students in the MPH program during preparation of this manuscript. This research was conducted during Dr. Maxwell's 12 months Visiting Professorship at the School of Public Health, Department of Public Health Medicine, University of Bielefeld, funded by the German Academic Exchange Service (DAAD).

\section{References}

I. Üstün TB, Chatterji S: Global Burden of Depressive Disorders and Future Projections. In Depression: Social and Economic Timebomb Edited by: Dawson A, Tylee A. London, BMJ Books ; 2001.

2. The changing rate of major depression. Cross-national comparisons. Cross-National Collaborative Group. Jama 1992, 268(2I):3098-3105.

3. Birmaher B, Ryan ND, Williamson DE, Brent DA, Kaufman J, Dahl RE, Perel J, Nelson B: Childhood and adolescent depression: a review of the past 10 years. Part I. J Am Acad Child Adolesc Psychiatry 1996, 35(I I): | 427-1439.

4. U.S. Department of Health and Human Services Mental Health: A Report of the Surgeon General. Rockville, MD , U.S. Department of Health and Human Services, Substance Abuse and Mental Health Services Administration, Center for Mental Health Services, National Institutes of Health, National Institute of Mental Health; 1999.

5. Saluja G, lachan R, Scheidt PC, Overpeck MD, Sun W, Giedd JN: Prevalence of and risk factors for depressive symptoms 
among young adolescents. Arch Pediatr Adolesc Med 2004, I 58(8):760-765

6. Roberts RE, Chen YR, Roberts CR: Ethnocultural differences in prevalence of adolescent suicidal behaviors. Suicide Life Threat Behav 1997, 27(2):208-217.

7. Lara M, Gamboa C, Kahramanian MI, Morales LS, Bautista DE: Acculturation and Latino health in the United States: a review of the literature and its sociopolitical context. Annu Rev Public Health 2005, 26:367-397.

8. Patten CA, Gillin JC, Farkas AJ, Gilpin EA, Berry CC, Pierce JP: Depressive symptoms in California adolescents: family structure and parental support. I Adolesc Health 1997, 20(4):27I-278.

9. Schraedley PK, Gotlib IH, Hayward C: Gender differences in correlates of depressive symptoms in adolescents. J Adolesc Health 1999, 25(2):98-108.

10. California Health Interview Survey (CHIS): Dataset public use file. 2003.

11. Radloff LS: The Use of the Center for Epidemiologic Studies Depression Scale in Adolescents and Young Adults. Journal of Youth and Adolescence 1991, 20:149-166.

12. Andresen EM, Malmgren JA, Carter WB, Patrick DL: Screening for depression in well older adults: evaluation of a short form of the CES-D (Center for Epidemiologic Studies Depression Scale). Am J Prev Med 1994, I0(2):77-84.

13. Roberts RE, Lewinsohn PM, Seeley JR: Screening for adolescent depression: a comparison of depression scales. J Am Acad Child Adolesc Psychiatry 1991, 30(I):58-66.

14. Roberts RE: Reliability of the CES-D Scale in different ethnic contexts. Psychiatry Res 1980, 2(2): I25-134.

15. Roberts RE: Manifestation of depressive symptoms among adolescents. A comparison of Mexican Americans with the majority and other minority populations. J Nerv Ment Dis 1992, | 80( I 0):627-633.

16. Crockett LJ, Randall BA, Shen YL, Russell ST, Driscoll AK: Measurement equivalence of the center for epidemiological studies depression scale for Latino and Anglo adolescents: a national study. J Consult Clin Psychol 2005, 73(I):47-58.

I7. Batista-Foguet JM, Fortiana J, Currie , R. VJ: Socio-economic indexes in surveys for comparisisons between countries. Social Indicators Research 2004, 67:3 I 5-332.

18. Hosmer DW, Lemeshow S: Applied logistic regression. In Wiley series in probability and statistics: texts and reference section 2nd edition. New York, Wiley-Interscience; 2000:373.

19. Greenberger E, Chen C, Tally SR, Qi D: Family, peer, and individual correlates of depressive symptomatology among U.S. and Chinese adolescents. I Consult Clin Psychol 2000, 68(2):209-219.

20. Kinds counts state-level data online: [www.kidscount.org].

21. Finch BK, Kolody B, Vega WA: Perceived discrimination and depression among Mexican-origin adults in California. J Health Soc Behav 2000, 4I(3):295-313.

22. Szalacha LA, Erkut S, Garcia Coll C, Alarcon O, Fields JP, Ceder Discrimination and Puerto Rican children's and adolescents' mental health. Cultur Divers Ethnic Minor Psychol 2003 9(2): $|4|-\mid 55$

23. Oppedal B, Roysamb E, Sam DL: The effect of acculturation and social support on change in mental health among young immigrants. Int I Behav Dev 2004, 28:48I-494.

24. La Greca AM, Harrison HM: Adolescent peer relations, friendships, and romantic relationships: do they predict social anxiety and depression? J Clin Child Adolesc Psychol 2005, 34(I):49-6I.

\section{Pre-publication history}

The pre-publication history for this paper can be accessed here:

http://www.biomedcentral.com/1471-2458/7/21/prepub
Publish with Bio Med Central and every scientist can read your work free of charge

"BioMed Central will be the most significant development for disseminating the results of biomedical research in our lifetime. "

Sir Paul Nurse, Cancer Research UK

Your research papers will be:

- available free of charge to the entire biomedical community

- peer reviewed and published immediately upon acceptance

- cited in PubMed and archived on PubMed Central

- yours - you keep the copyright
BioMedcentral 